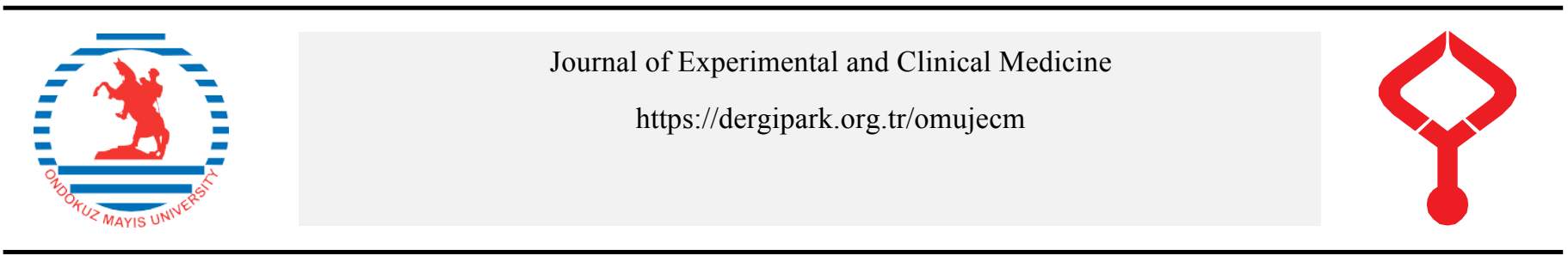

Research Article

J Exp Clin Med

2021; 38(2): 82-87

doi: $10.52142 /$ omujecm.38.2.5

\title{
An investigation of histopathologic and morphometric effect of black carrot juice on acrylamid induced neurotoxicity
}

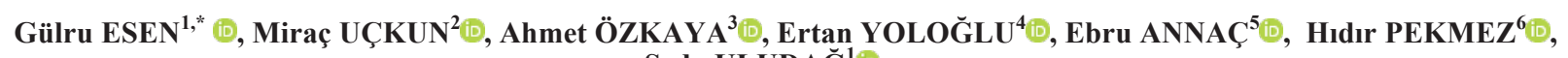 \\ Seda ULUDAĞ' $\breve{1}^{1}$
}

\author{
${ }^{1}$ Department of Anatomy, Faculty of Medicine, Adiyaman University, Adiyaman, Turkey \\ ${ }^{2}$ Department of Food Engineering, Faculty of Engineering, Adıyaman University, Adıyaman, Turkey \\ ${ }^{3}$ Department of Chemistry, Faculty of Science-Literature, Adıyaman University, Adiyaman, Turkey \\ ${ }^{4}$ Department of Mathematics and Science Education, Faculty of Education, Adiyaman University, Adiyaman, Turkey \\ ${ }^{5}$ Department of Histology and Embryology, Faculty of Medicine, Adiyaman University, Adiyaman, Turkey \\ ${ }^{6}$ Department of Anatomy, Faculty of Medicine, Malatya Turgut Özal University, Malatya, Turkey
}

\begin{abstract}
$\begin{array}{llll}\text { Received: } 23.12 .2020 & \bullet & \text { Accepted/Published Online: } 16.01 .2021 & \text { Final Version: } 14.03 .2021\end{array}$
Abstract

Acrylamide is an organic compound that is known to have neurotoxic influences. People have high exposure to its impacts because of its extensive uses in the industrial fields and its occurrence in foods. This situation has induced the scientific word to identify naturel components that may eliminate these neurotoxic effects. In this experimental study the influence of black carrot juice containing bioavailable flavonoids was researched on acrylamide neurotoxicity. In the study, laboratory rats were divided in to four groups. Group 1 rats were the control group. While the rats in Group 2 were administered acrylamide substance, the rats in Group 3 were supplemented with black carrot juice + acrylamide, and the rats in Group 4 were given black carrots juice only. At the experiment's end, biochemical, histopathological, and histomorphometry analysis were performed on exanguned rats. Significant histopathological degenerations were observed in the acrylamide treated group. Despite a volumetric degrease in all brain regions examined histomorphometrically, this decrease was not statistically significant. The malondialdehyde and Glutathione S-transferase levels of the acrylamide group showed a significant increase compared to the control group. The glutathione, carboxylesterase and acetylcholinesterase levels were observed to increase in the acrylamide and black carrot applied group, compared to the acrylamide group. This study's findings have revealed the black carrot's healing effects on acrylamide neurotoxicity.
\end{abstract}

Keywords: Acrylamide, neurotoxicity, black carrot, histopathology, morphometry

\section{Introduction}

Acrylamide (ACR) is a vinyl monomer with the molecular formula of $\mathrm{CH} 2=\mathrm{CH}-\mathrm{CO}-\mathrm{NH} 2$. It is a colorless, solid, odorless, easily soluble in water and organic solvents (Shrivastava et al., 2018; Tabeshpour et al., 2019). It is widely used in the industrial field (Dasari et al., 2018a; Tabeshpour et al., 2019; Abdel-Daim et al., 2020). Recently, it has been discovered that high temperature exposure during the cooking of carbohydrate- rich food induces acrylamide formation as a result of the Maillard reaction. Acrylamide is formed during cooking of foods with a with a high starch rate, such as bread, French fries, chips, breakfast cereals, biscuits, cakes at $120^{\circ} \mathrm{C}$ and above temperatures (Kopanska et al., 2017; Shrivastava et al., 2018; Dasari et al., 2018b). Besides occupational exposures, especially children are at risk of having exposure to acrylamide in Daily food. Indeed, the exposure of people to the toxicity (neurotoxicity, hepatotoxicity, genotoxicity, carcinogenicity, reproductive toxicity) has created a global concern against acrylamide due to its wide spread use in the environmental and endustial field (Kopanska et al., 2017). The toxic effects of acrylamide on the nervous system are known (Shrivastava et al., 2018; Dasari et al., 2018a; Lee et al., 2018; Dortaj et al., 2018).

Effect of natural antioxidants against acrylamide toxicity continues to attract attention. However, there is no study in the literature on the influence of black carrot. Although orange carrot varieties are more common, consumption of black carrot containing vitC, $\mathrm{E}$ and phenol compounds, is increasing worldwide because of its positive effects on health. Black carrot attracts the scientific community's attention due to its antioxidant properties (Ulusoy and Tamer, 2019). It contains more total anthocyanidins than some other red fruits 
(Garcia Herrera et al., 2016; Kamiloglu et al., 2018). Anthocyanins have antidiabetic, anti-inflammatory, antimicrobial, anticancer, anti-obesitic effects as well as preventing cardiovascular diseases. Nutritionally, anthocyanin bioavailability is a significant factor in these protective effects. From this perspective, the anthocyanin variety found in black carrot is one of the two types with the highest bioavailability (Algarra et al., 2014; Mizgier et al., 2016; Khoo et al., 2017). Based on these studies we aimed to examine morphologically the effects of black carrot juice on acrylamide neurotoxicity.

\section{Materials and methods}

The study started with the permission obtained from the animal experiments local ethics committee of the relevant university. The permission number is 2019/043. The test animals were obtained from the same university, the Experimental Animal Production Application and Research Center. In the study, 32 male Wistar Albino rats, weighing Table 1: Experimental design and applications between 200-250 g, aged 10-12 weeks were randomly selected and divided into four groups. During the study the rats were housed in rooms at a temperature of $22 \pm 2{ }^{\circ} \mathrm{C}$, with a 12 hours light and 12 hours dark cycle and ad-libitum feet and water. The experiment lasted a total of 30 days. Each group consisted of eight animals placed in two separate cages each of which contains four mice. Groups and applications are shown in Table 1. Acrylamide used in the study was provided from ACROS ORGANICS. The application was made according to the method of Chao Yi et al. (Yi et al., 2006). Fresh black carrots obtained from the local market were washed in tap water, cut into smaller pieces, and squeezed in a juicer, and immediately fed to the animals freshly. Exanguination was applied to all rats in all groups at the end of the 30-day experiment period. Brain tissues were taken into $10 \%$ formaldehyde. Histopathological, histomorphometry, and biochemical analyzes were performed on the brain tissues.

\begin{tabular}{lccccc} 
& $\begin{array}{c}\text { Animal } \\
\text { number }\end{array}$ & Agent & $\begin{array}{c}\text { Application } \\
\text { method }\end{array}$ & $\begin{array}{c}\text { Dose } \\
\text { frequency }\end{array}$ \\
\hline Control group & 8 & none & & & \\
Black carrot juice group & 8 & black carrot & oral gavage & $1 \mathrm{ml}$ & every other day \\
$\begin{array}{l}\text { Acrylamide group } \\
\text { Acrylamide }+ \text { Black }\end{array}$ & 8 & acrylamide & intraperitoneal & $20 \mathrm{mg} / \mathrm{kg}$ & every other day \\
Carrot juice group & 8 & acrylamide & intraperitoneal & $20 \mathrm{mg} / \mathrm{kg}$ & every other day \\
black carrot & oral gavage & $1 \mathrm{ml}$ & every other day
\end{tabular}

\subsection{Histopathological analysis}

After the experimental phase completed, the brain tissues were obtained and fixed with $10 \%$ formaldehyde. Then, dehydration and polishing processes were performed according to the routine histological tissue follow-up procedure. Tissues that were followed-up were turned into paraffin blocks. For histological examination, $5 \mu \mathrm{m}$ thick sections were obtained from the paraffin blocks. The sections obtained were deparaffinized and cresyl violet staining method was applied. The stained pieces were examined with Carl Zeiss brand Axiocam ERc5 model digital camera attachment microscope and evaluated histopathologically.

\subsection{Histomorphometry measurements}

For analysis from brain tissues, 40- serial sections with 10 micrometers thickness were selected with 1/20 sampling rate. Volumes of the CA1 + CA2, CA3, and dentate gyrus regions in the hippocampus were calculated through the photographs taken from the sections. For these measurements, the "closed polygon calculation" tool in the Image $J$ software program was selected. Volume $=$ Calculated area $\mathrm{x}$ Sampling rate $\mathrm{x}$ Section thickness formula was used to calculate the volume by drawing the relevant area (Fig.2).

\subsection{Biochemical analysis}

Tissue samples were homogenized with the homogenizer (Heidolph RZ 2021, Germany) in chilled potassium phosphate buffer (0.1 M, pH 7.4; 0.15M KCl, 1 mM EDTA, 1

$\mathrm{mM}$ DTT). Five hundred microliters of homogenate were allocated for MDA (malondialdehyde) analysis. The remaining homogenates were centrifuged at $16.000 \mathrm{x}$ g for 20 minutes at $4{ }^{\circ} \mathrm{C}$ (Hettich $460 \mathrm{R}$ ) and then supernatants (S16) were transferred to eppendorf tubes for measurements of biomarkers except for MDA. MDA- levels of tissue samples were examined according to the Placer et al.'s method (Placer et al., 1966). The absorbances of the obtained samples was read spectrophotometrically (ThermoTM Varioskan Flash, Finland) at $532 \mathrm{~nm}$. The MDA level was expressed as nmol/ $\mathrm{mg}$ protein. The amount of GSH (glutathione) was measured using the Moron et al.'s method (Moron et al., 1979). The absorbances of the samples were spectrophotometrically observed (ThermoTM Varioskan Flash, Finland) at $412 \mathrm{~nm}$. GSH level is stated as nmol/ $\mathrm{mg}$ protein.

GST (Glutathione S-transferase) activity was worked by the method reported by Habiig et al. (Habig et al., 1974). Specific GST activity was calculated as $\mathrm{nmol} / \mathrm{min} / \mathrm{mg}$ protein. Carboxylesterases (CAE) activity measured using the Nousiainen et al. method, was expressed as nmol / $\mathrm{min} / \mathrm{mg}$ protein (Nousiainen and Törrönen, 1984). Brain AChE (acetylcholinesterase) activity was analyzed according to the method described by Ellman and Andres, with a modification of a microplate reader spectropho $\neg$ tometer system (ThermoTM Varioskan Flash, Thermo Scientific, Vantaa, Finland) (Ellman et al., 1961; Özmen et al., 1998). 
The total protein amounts in the tissue homogenates were defined according to the method developed by Bradford (Bradford, 1976). Subject to the color change, the absorbance value was determined at a wavelength of $595 \mathrm{~nm}$.

\section{Results}

\subsection{Histopathological findings}

It was determined that the general structure of the neurons in cortex, hippocampus, and dentate gyrus regions were normal in the control group sections. The perikaryon borders were observed to be smooth, and their shapes were pyramidal. The nuclei of the cells were euchromatic, and their nucleoli was prominent. It was also observed that the neuroglia cells were in normal appearance (Figs. 1; 1a, 1b and 1c). It was found that the neurons were healthy, with a pyramidal shape, and well-circumscribed precarious in the examination performed in the black carrot group. A histological structure was observed to be similar to the control group (Figs. 1; 2a, 2b and $2 \mathrm{c}$ ).
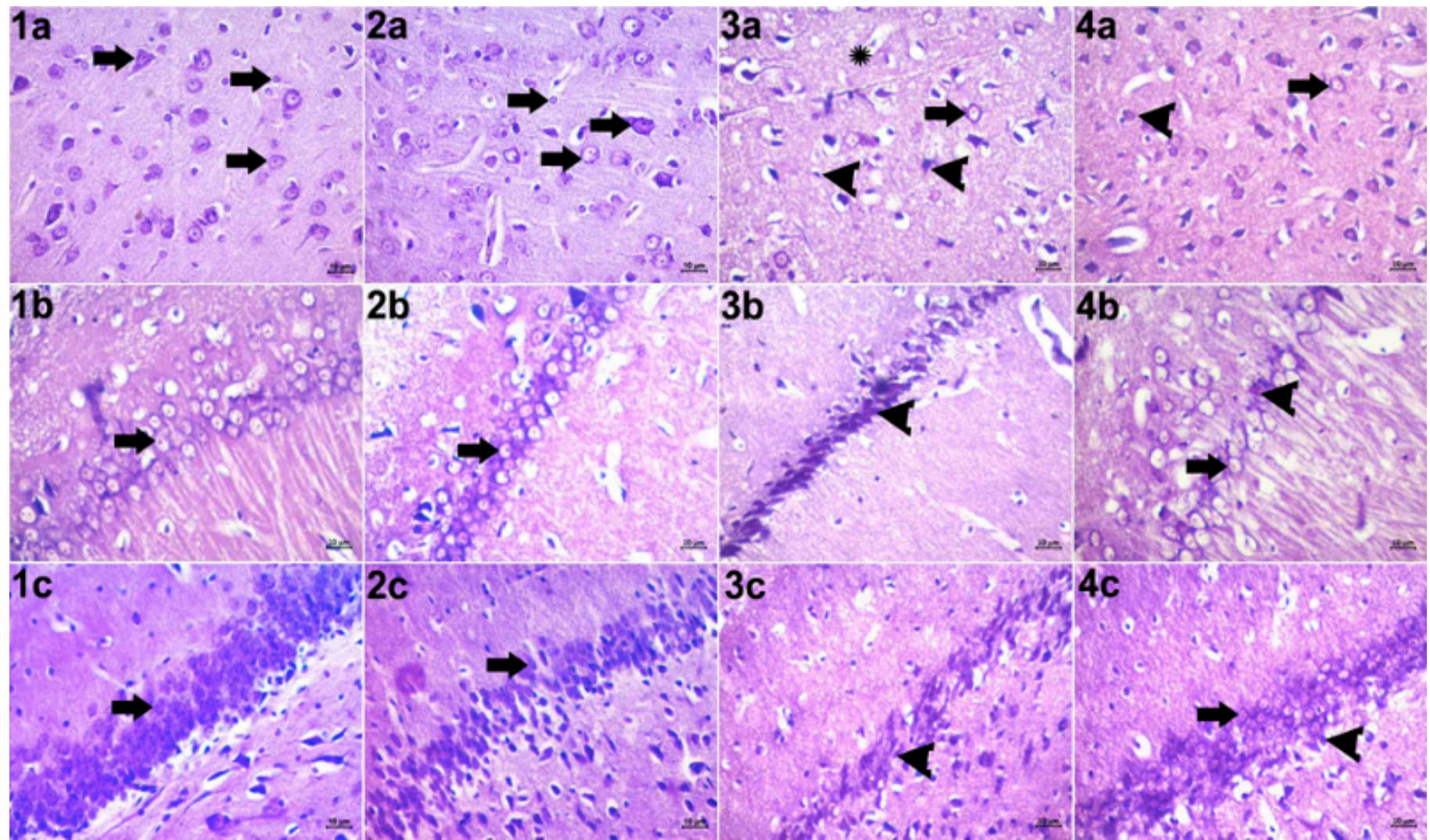

Fig. 1. Objective images of $x 40$ from different parts of the brain tissue belonging to the groups. 1a, $\mathrm{b}$ and $\mathrm{c}$; Images of the control group, $2 \mathrm{a}, \mathrm{b}$ and c; Images of the black carrot applied group, 3a, b and c; Images of the acrylamide applied group; 4a, b and c; Images of the acrylamide + black carrot applied group (a, b and c cortex cerebri, hippocampus and dentate gyrus regions, respectively); Bold arrow; Healthy neurons in the cortex cerebrum, hippocampus and dentate gyrus regions are stars; Perineural vacuolization, arrowhead; Degenerate neurons (Cresyl violet staining).

Table 2. Histomorphometric analysis results of brain tissue $\left(\mathrm{mm}^{3}\right)$

\begin{tabular}{|c|c|c|c|}
\hline Groups & $\mathrm{CA} 1+\mathrm{CA} 2$ & CA3 & Dentate Gyrus \\
\hline control & $294.6 \pm 19.5$ & $259.5 \pm 57.2$ & $220.6 \pm 21.4$ \\
\hline Black carrot & $265.7 \pm 16.6$ & $238.1 \pm 17.4$ & $242.7 \pm 22.3$ \\
\hline Acrylamide & $231.6 \pm 17.2$ & $183.6 \pm 22.1$ & $206.1 \pm 40.1$ \\
\hline Acrylamide + Black carrot & $279.1 \pm 26.7$ & $217.5 \pm 73.3$ & $215.8 \pm 25.3$ \\
\hline
\end{tabular}

* $(\mathrm{p}>0.05)$ no statistically differences among groups

Both cell and nuclear boundaries of the neurons were in an irregular appearance in the light microscopic evaluation of the acrylamide applied group. In addition to degenerated neurons, there were signs of cellular edema in some neurons. It was noticed that the nuclei belonging to mostly neurons had a dark pyknotic appearance in contrast to the control and black carrot groups. An increase in the perineural vacuolization rate was observed. (Figs. $1 ; 3 a, 3 b$ and $3 c$ ). In the study of the acrylamide plus black carrot group, the histological structures of most of the neurons were found to be similar to those of the control and black carrot groups. However, due to the acrylamide effect, among the normal 
structure neurons, it was encountered to the nuclei with diminished chromatin; neurons having narrow and dark stained cytoplasm; together with a dark basophilic nucleus, pyramidal neurons with dark stained, irregularly demarcated cytoplasm. Neuroglia cells were also found to be normal and healthy (Figs. 1- 4a, 4b, and 4c). In the examination, no lesions or hyperemia findings were found in the tissues belonging to the groups.

\subsection{Histomorphometric findings}

Volume $=$ Calculated area $\mathrm{x}$ Sampling rate $\mathrm{x}$ Section thickness formula was used for the volume calculation by drawing the relevant area on the "closed polygon calculation" program included in the image $\mathrm{j}$ software (Fig. 2).

As a result, a volumetric reduction was determined in all regions in the acrylamide group compared to the control group. However, when calculated statistically, it was found that this decrease did not create a significant difference between the groups ( $\mathrm{p}>0.05)$ (Table 2) (Figs. 3, 4, 5).

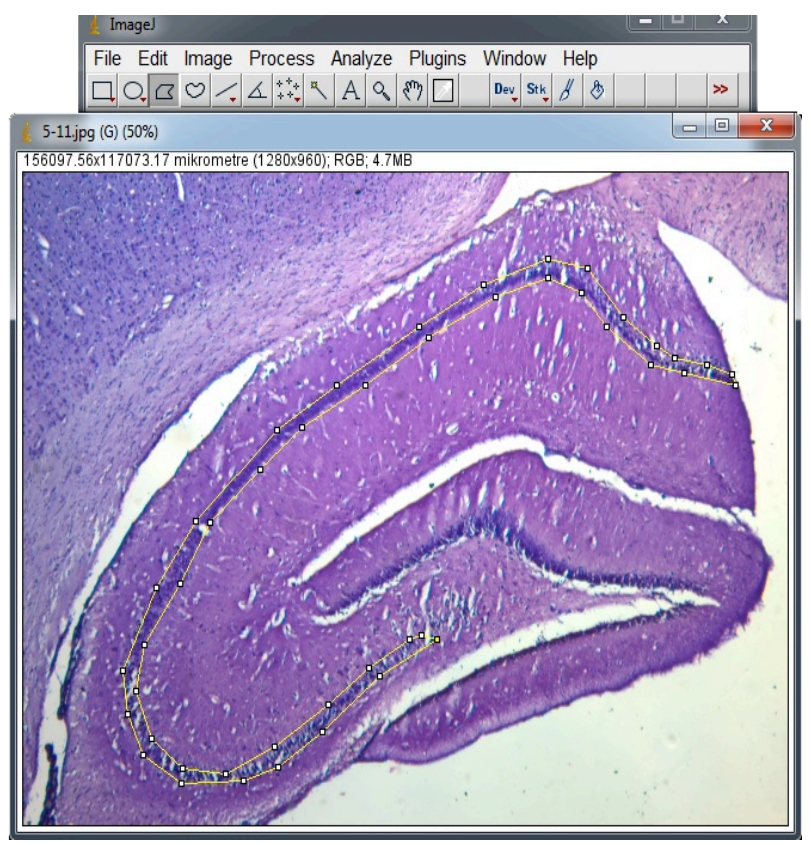

Fig. 2. Image j software program used in volumetric analysis

\subsection{Biochemical findings}

MDA, GSH, GST, CAE, and AChE levels of the brain tissue are given in Table 3 .

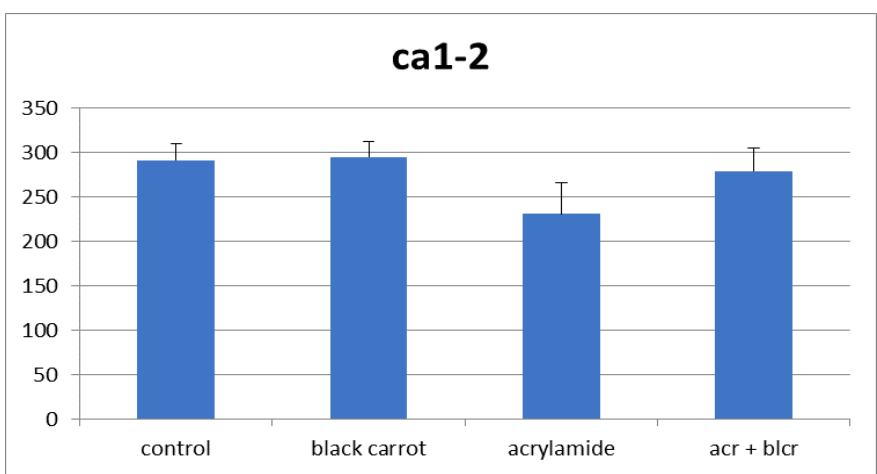

Fig. 3. Volumetric measurements of CA1-2 regions of the hippocampus

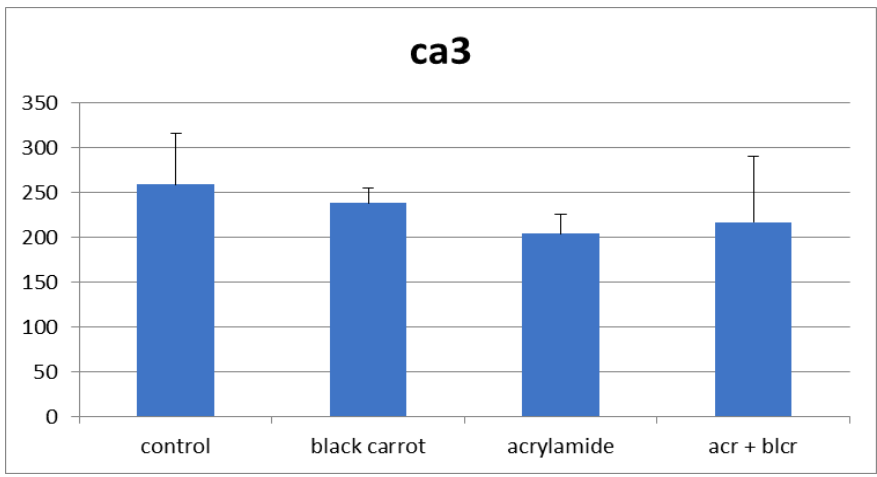

Fig. 4. Volumetric measurements of the CA3 region of the hippocampus

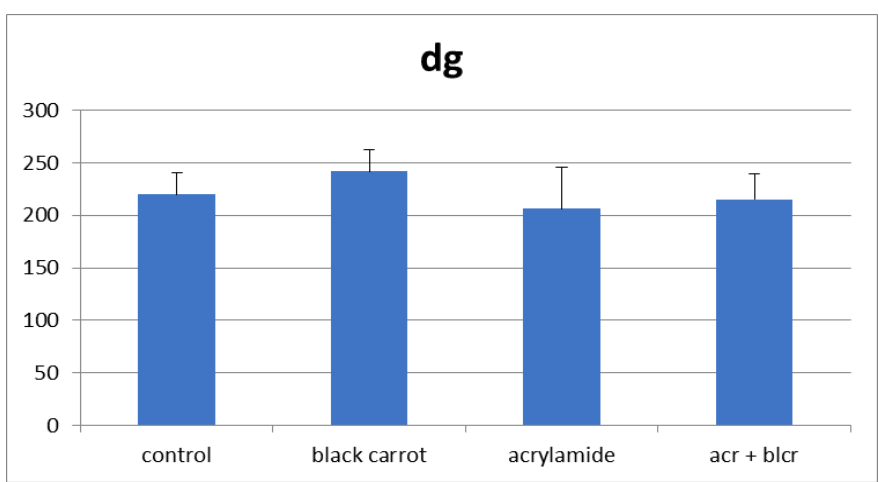

Fig. 5. Volumetric measurements of the gyrus dentatus

Table 3. Brain biochemical parameters in Control, Acrylamide, Black Carrot and Acrylamide + Black Carrot treated group. Values are expressed as means $\pm \mathrm{SE} ; \mathrm{n}=8$ for each treatment group

\begin{tabular}{lccccc|} 
Groups & $\begin{array}{c}\text { MDA } \\
\text { (nmol/mg } \\
\text { protein) }\end{array}$ & $\begin{array}{c}\text { GSH } \\
\text { (nmol/mg } \\
\text { protein) }\end{array}$ & $\begin{array}{c}\text { GST } \\
\text { (nmol/min/mg } \\
\text { protein) }\end{array}$ & $\begin{array}{c}\text { CAE } \\
\text { (nmol/min/mg } \\
\text { protein) }\end{array}$ & $\begin{array}{c}\text { AChE } \\
\text { (nmol/min/mg } \\
\text { protein) }\end{array}$ \\
\hline Control & $79.4 \pm 2.7$ & $55.3 \pm 1.5$ & $20.2 \pm 0.43$ & $33.74 \pm 1.19$ & $25.17 \pm 0.81$ \\
Acrylamide & $116.2 \pm 3.3^{\mathrm{c}}$ & $34.8 \pm 0.9^{\mathrm{b}}$ & $32.4 \pm 0.48^{\mathrm{c}}$ & $25.76 \pm 0.51^{\mathrm{c}}$ & $19.55 \pm 0.19^{\mathrm{b}}$ \\
Black carrot & $90.3 \pm 2.1^{\mathrm{z}}$ & $48.8 \pm 4.1^{\mathrm{x}}$ & $29.1 \pm 0.33^{\mathrm{cy}}$ & $30.59 \pm 0.44^{\mathrm{x}}$ & $23.05 \pm 1.38^{\mathrm{x}}$ \\
$\begin{array}{l}\text { Acrylamide+black } \\
\text { carrot }\end{array}$ & $92.6 \pm 3.2^{\mathrm{z}}$ & $47.2 \pm 2.3^{\mathrm{x}}$ & $27.3 \pm 0.28^{\mathrm{cz}}$ & $33.02 \pm 1.31^{\mathrm{z}}$ & $23.20 \pm 0.86^{\mathrm{x}}$
\end{tabular}

Statistical significancy compared to the control group: a: $\mathrm{p}<0.05$; $\mathrm{b}$ : $\mathrm{p}<0.01$, c: $\mathrm{p}<0.001$

\section{Discussion}

In this study, histopathological findings revealed that acrylamide causes pathological changes at the cell level. In rats treated with acrylamide, although black carrot juice had positive cellular impacts, it was observed that it could not eliminate acrylamide effects at the nucleus level.

In terms of histomorphometric measurements, volumetric reductions were detected in all zones of the brain tissue examined in the acrylamide group. This decrease was not 
statistically significant and no differences were observed in the other groups, thus suggesting that the doses and frequencies of both acrylamide and black carrot application did not entirely cause morphometric changes. Cell counts were not performed in our study. Otherwise, more significant results could have been encountered.

In terms of the biochemical data, statistically significant differences were detected in the acrylamide group compared to the control group, both in parameters showing oxidative stress and also the AChE level indicating neurodegeneration. These data suggest that acrylamide causes neurodegeneration through oxidative stress. When compared to the acrylamide group, there was a statistically significant decrease in all parameters in the black carrot group. However, the lack of difference between the black carrot group and the control group showed that the black carrot did not make any difference in the normal tissue. In terms of the acrylamide + black carrot applied group, we observed that there were statistically significant differences between the acrylamide group. There was no significant difference with the control group. These data indicated the reconditioning influence of black carrots on oxidative stress and neurodegeneration caused by acrylamide.

Oxidative stress is among the most critical mechanisms of neurodegeneration caused by acrylamide. It has been reported that after the ACR application, lipid peroxidation increases, and antioxidant capacity in nerve tissue decreases. On the other hand, it has experimentally been shown that MDA, as a biomarker of lipid peroxidation in various diseases containing neurodegenerative diseases, increases as a result of ACR exposure (Tabeshpour et al., 2019). Glutathione S-transferase (GST) is one of the prominent antioxidant enzymes. Glutathione S-transferases is a multifunctional dimeric protein involved in cellular detoxification of reactive electrophilic compounds and protecting tissues from oxidative damage (Dasari et al., 2018a). It has also been reported in the literature that acrylamide administration causes a decrease in acetylcholinesterase activity (Kopanska et al., 2017). Carboxylesterases are enzymes required for the metabolization of drugs, prodrugs, some pesticides, and endogenous compounds (Di, 2019). Organophosphorus and carbamate pesticides cause inhibition of acetylcholinesterase (AChE, the target enzyme) and carboxylesterase. However, $\mathrm{CE}$ is more sensitive to some exogenous components; therefore, it is claimed that $\mathrm{CE}$ has a protective effect on AChE (Soto-Mancera et al., 2020). In our study, it is seen that $\mathrm{CE}$ decreased in the brain tissue of acrylamide-treated rats compared to the control group, just like AChE, and increased in the groups treated with black carrot and acrylamide+black carrot compared to the acrylamide group. Based on these data, it can be said that $\mathrm{CE}$ and AChE have the same level of acrylamide affinity, and black carrot application has brought $\mathrm{CE}$ level to control group levels. In a study, which Vit E effects were examined on acrylamide damage, was reported that MDA level increased significantly in rats treated with acrylamide compared to the control group, while GSH level decreased (Erdemli et al., 2020). The researchers stated that glial cell infiltration, congestion, and bleeding were significantly higher in the AA treated group histopathologically, and cortical thickness was significantly less than all other groups. In brain tissue sections, they reported that the cell structure was regular in most parts of the cortical region, but vacuolization was observed in the molecular layer. Different degrees of glial cell infiltration and inflammatory cell infiltration in the cortex were among the data also. The tending of neuron/glial cell ratio in the cortex towards glial cells was also among the findings reported in the study. Guo Jie et al. examined the effect of curcumin on the damage caused by acrylamide in their studies (Guo et al., 2020). The study indicated that ACR-treated rats had a severe neuronal loss, densified and fragmented nuclei in the cortex and hippocampus, and more nerve cells and less pathology were observed in the curcumin-treated rats' brains compared to the ACR group. In the same study, it was emphasized that the GSH level decreased significantly in the cerebral homogenates of the rats treated with ACR compared to the regular control group, and the MDA content increased significantly, suggesting ACR-induced oxidative stress in the brain. Atwa Asmaa Husseiny et al. mentioned in their study that light microscopic examination of brain sections in rats treated with $15 \mathrm{mg} / \mathrm{kg}$ acrylamide showed shrunken pyramidal cells surrounded by empty spaces (Atwa, 2020). Among other findings, apoptotic cells with small dark stained nuclei and acidophilic cytoplasm surrounded by space; dilated and clogged blood vessels were reported. The researchers reported a highly significant increase in serum MDA levels in the acrylamide group, acrylamide + garlic oil group, and acrylamide + rosemary extract group compared to the negative control group. However, they also reported that coadministration of garlic oil and rosemary extract with acrylamide resulted in a significant decrease in MDA compared to the AA-treated group. They also mentioned statistically significant high decreases in the activity of acetylcholinesterase enzyme in the brain tissue of the acrylamide-treated group, the AA + garlic oil group, and the $\mathrm{AA}+$ rosemary extract group compared to the negative control group. There is no information in the literature about the effects of black carrots on acrylamide neurotoxicity. Our study contributes to the literature in terms of that it tries to enlighten this issue through histomorphometric data as well as histopathological and biochemical parameters. On the other hand, the fact that behavioral tests and cell count could not have been performed constitutes the study's limitations.

Ethics approval Experimental animals local ethics committee (2019/043)

Conflict of interest

There is no conflict of interest

\section{Fundings}

There is no funding 


\section{References}

1. Abdel-Daim, M.M., El-Ela, F.I.A., Alshahrani, F.K., Bin-Jumah, M., Al-Zharani, M., Almutairi, B., Alyousif, M.S., Bungau, S., Aleya, L., Alkahtani, S., 2020. Protective effects of thymoquinone against acrylamide-induced liver, kidney and brain oxidative damage in rats. Environ. Sci. Pollut. Res. Int. 1-9.

2. Algarra, M., Fernandes, A., Mateus, N., de Freitas, V., da Silva, J.C.E., Casado, J., 2014. Anthocyanin profile and antioxidant capacity of black carrots (Daucus carota L. ssp. sativus var. atrorubens Alef.) from Cuevas Bajas, Spain. J. Food. Compost. Anal. 33, 71-76.

3. Atwa, A.H., 2020. A study of The Possible Protective Effects of Garlic Oil and Rosemary Extract Against Some Toxic effects of Acrylamid on Adult Male Albino Rats. ZJFM. 18, 68-91.

4. Dasari, S., Ganjayi, M.S., Gonuguntla, S., Ramineedu, K., Konda, P.Y., Meriga, B., 2018a. Assessment of biomarkers in acrylamide-induced neurotoxicity and brain histopathology in rat. J. appl. biol. Biotechnol. Vol. 6, 79-86.

5. Dasari, S., Ganjayi, M.S., Meriga, B., 2018b. Glutathione Stransferase is a good biomarker in acrylamide induced neurotoxicity and genotoxicity. Interdisciplinary Toxicology. 11, $115-121$.

6. Di, L., 2019. The impact of carboxylesterases in drug metabolism and pharmacokinetics. Curr. Drug. Metab. 20, 91102.

7. Dortaj, H., Yadegari, M., Abad, M.H.S., Sarcheshmeh, A.A., Anvari, M., 2018. Stereological method for assessing the effect of vitamin $\mathrm{C}$ administration on the reduction of acrylamideinduced neurotoxicity. Basic Clin. Neurosci. 9, 27.

8. Ellman, G.L., Courtney, K.D., Andres Jr, V., Featherstone, R.M., 1961. A new and rapid colorimetric determination of acetylcholinesterase activity. Biochem. Pharmacol. 7, 88-95.

9. Erdemli, Z., Erdemli, M.E., Turkoz, Y., Yigitcan, B., Aladag, M.A., Cigremis, Y., Cırık, R.H., Altinoz, E., Bag, H.G., 2020. Vitamin $\mathrm{E}$ effects on developmental disorders in fetuses and cognitive dysfunction in adults following acrylamide treatment during pregnancy. Biotech. Histochem. 1-9.

10. Garcia Herrera, P., Pérez Rodríguez, M.L., Aguilera Delgado, T., Labari Reyes, M.J., Olmedilla Alonso, B., Camara, M., de Pascual Teresa, S., 2016. Anthocyanin profile of red fruits and black carrot juices, purees and concentrates by HPLC DAD ESI/MS QTOF. J. Food Sci. Technol. 51, 2290-2300.

11. Guo, J., Cao, X., Hu, X., Li, S., Wang, J., 2020. The antiapoptotic, antioxidant and anti-inflammatory effects of curcumin on acrylamide-induced neurotoxicity in rats. BMC. Pharmacol. Toxicol. 21, 1-10.

12. Habig, W.H., Pabst, M.J., Jakoby, W.B., 1974. Glutathione Stransferases the first enzymatic step in mercapturic acid formation. J. Biol. Chem. 249, 7130-7139.

13. Kamiloglu, S., Van Camp, J., Capanoglu, E., 2018. Black carrot polyphenols: Effect of processing, storage and digestion-An overview. Phytochem. Rev. 17, 379-395.

14. Khoo, H.E., Azlan, A., Tang, S.T., Lim, S.M., 2017. Anthocyanidins and anthocyanins: colored pigments as food, pharmaceutical ingredients, and the potential health benefits. Food. Nutr. Res. 61, 1361779.

15. Kopanska, M., Czech, J., Zagata, P., Dobrek, L., Thor, P., Formicki, G., 2017. Effect of the different doses of acrylamide on acetylocholinoesterase activity, thiol groups, malondialdehyde concentrations in hypothalamus and selected muscles of mice. J. Physiol. Pharmacol. 68, 565-571.

16. Lee, S., Park, H.R., Lee, J.Y., Cho, J.-H., Song, H.M., Kim, A.H., Lee, W., Lee, Y., Chang, S.-C., Kim, H.S., 2018. Learning, memory deficits, and impaired neuronal maturation attributed to acrylamide. J. Toxicol. Environ. Health Part A 81, 254-265.

17. Mizgier, P., Kucharska, A.Z., Sokół-Łętowska, A., KolniakOstek, J., Kidoń, M., Fecka, I., 2016. Characterization of phenolic compounds and antioxidant and anti-inflammatory properties of red cabbage and purple carrot extracts. J. Funct. Foods 21, 133-146.

18. Moron, M.S., Depierre, J.W., Mannervik, B., 1979. Levels of glutathione, glutathione reductase and glutathione S-transferase activities in rat lung and liver. Biochim. Biophys. Acta. 582, 6778.

19. Nousiainen, U., Törrönen, R., 1984. Differentiation of microsomal and cytosolic carboxylesterases in the rat liver by in vivo and in vitro inhibition. Gen. Pharmacol. 15, 223.

20. Özmen, M., Dominguez, S., Fairbrother, A., 1998. Effects of dietary azinphos methyl on selected plasma and tissue biomarkers of the gray-tailed vole. Bull. Environ. Contam. Toxicol. 60, 194-201.

21. Placer, Z.A., Cushman, L.L., Johnson, B.C., 1966. Estimation of product of lipid peroxidation (malonyl dialdehyde) in biochemical systems. Anal. Biochem. 16, 359-364.

22. Shrivastava, S., Uthra, C., Reshi, M., Singh, A., Yadav, D., Shukla, S., 2018. Protective effect of hesperetin against acrylamide induced acute toxicity in rats.

23. Soto-Mancera, F., Arellano, J., Albendín, M., 2020. Carboxylesterase in Sparus aurata: Characterisation and sensitivity to organophosphorus pesticides and pharmaceutical products. Ecol. Indic. 109, 105603.

24. Tabeshpour, J., Mehri, S., Abnous, K., Hosseinzadeh, H., 2019. Neuroprotective effects of thymoquinone in acrylamide-induced peripheral nervous system toxicity through MAPKinase and apoptosis pathways in rat. Neurochem. Res. 44, 1101-1112.

25. Ulusoy, A., Tamer, C.E., 2019. Determination of suitability of black carrot (Daucus carota L. spp. sativus var. atrorubens Alef.) juice concentrate, cherry laurel (Prunus laurocerasus), blackthorn (Prunus spinosa) and red raspberry (Rubus ideaus) for kombucha beverage production. J. Food. Meas. 13, 1524-1536.

26. Yi, C., Xie, K., Song, F., Yu, L., Zhao, X., Li, G., Yu, S., 2006. The changes of cytoskeletal proteins in plasma of acrylamideinduced rats. Neurochem. Res. 31, 751-757. 